\title{
Comparison of "Lesion-by-Lesion" and Field Photodynamic Therapy in the Prevention of Actinic Keratoses: A Randomized, Split-Face, Single-Blind Pilot Study
}

\author{
Inge Seubring ${ }^{\mathrm{a}}$ Joannes M. M. Groenewoud ${ }^{\mathrm{b}}$ Marie-Jeanne P. Gerritsen ${ }^{\mathrm{a}}$ \\ Departments of a Dermatology and ${ }^{b}$ Health Evidence, Radboud University Medical Center, Nijmegen, \\ The Netherlands
}

\section{Keywords}

In-patient comparison - Field photodynamic therapy · Lesion-by-lesion photodynamic therapy · Prevention

\begin{abstract}
Background: Actinic keratoses (AKs) are often treated separately, lesion by lesion. However, in the past years, AKs have been described as a field disease and not limited to single clinically apparent lesions. Treatment should therefore target an area of field change which may reduce the risk of development of further AKs, second tumours, and local recurrence. Objective: The primary objective was to determine the number of new lesions at 9 months after methyl aminolevulinate photodynamic therapy (MAL-PDT). Secondary objectives were to determine the number of new lesions at 3 and 6 months after treatment and the percentage reduction of AKs from baseline at 3, 6, and 9 months after MALPDT. Methods: This was a single-centre, prospective, randomized, split-face, investigator-blinded pilot study with a study duration of 1 year. The study population comprised patients with AKs on the face or scalp, with a maximum of 10 AKs on each side. One side was treated with 1 session of "lesion-by-lesion" MAL-PDT (LT side) and the other side with 1 session of field MAL-PDT (FT side). Results: At 9 months the
\end{abstract}

FT demonstrated significantly fewer new lesions. At every time point during the follow-up, we found a significant reduction in the number of AKs in the LT as well as in the FT sides. After 3 and 6 months we did not observe significant differences between the sides. However, after 9 months, the LT area showed significantly fewer remaining AKs, whereas the FT area demonstrated significantly fewer new lesions. Conclusions: Field treatment results in significantly fewer new AK lesions compared with lesion-by-lesion treatment.

$$
\begin{aligned}
& \text { @ } 2017 \text { The Author(s) } \\
& \text { Published by S. Karger AG, Basel }
\end{aligned}
$$

\section{Introduction}

Actinic keratoses (AKs) are the most common premalignancies of the skin. If left untreated they may evolve into squamous cell carcinomas (SCCs). In the past, AKs were mainly seen in the elderly. However, the incidence of skin (pre)malignancies is rising rapidly, and more and more young patients show multiple skin tumours. In the Netherlands, in 2012, we encountered 160,000 patients with AKs [1]. In the past, AKs were treated lesion by lesion, mainly with liquid nitrogen or topical 5-fluorouracil cream [2]. Several years ago, Metvix (methyl aminolevulinate, MAL) was approved for the treatment of AK. Met-

\begin{tabular}{ll}
\hline KARGER & $\begin{array}{l}\text { @ } 2017 \text { The Author(s) } \\
\text { Published by S. Karger AG, Basel }\end{array}$ \\
& $1018-8665 / 17 / 2326-0708 \$ 39.50 / 0$ \\
E-Mail karger@karger.com & Open \\
www.karger.com/drm & This article is licensed under the Creative Commons Attribution- \\
& NonCommercial-NoDerivatives 4.0 International License (CC BY- \\
& NC-ND) (http://www.karger.com/Services/OpenAccessLicense). \\
& Usage and distribution for commercial purposes as well as any dis- \\
tribution of modified material requires written permission.
\end{tabular}

Prof. Dr. M.-J.P. Gerritsen

Department of Dermatology

Radboud University Medical Center, PO Box 9101

NL-6500 HB Nijmegen (The Netherlands)

E-Mail rianne.gerritsen@ radboudumc.nl 
Fig. 1. Flowchart of Materials and Methods. AK, actinic keratosis; PDT, photodynamic therapy.

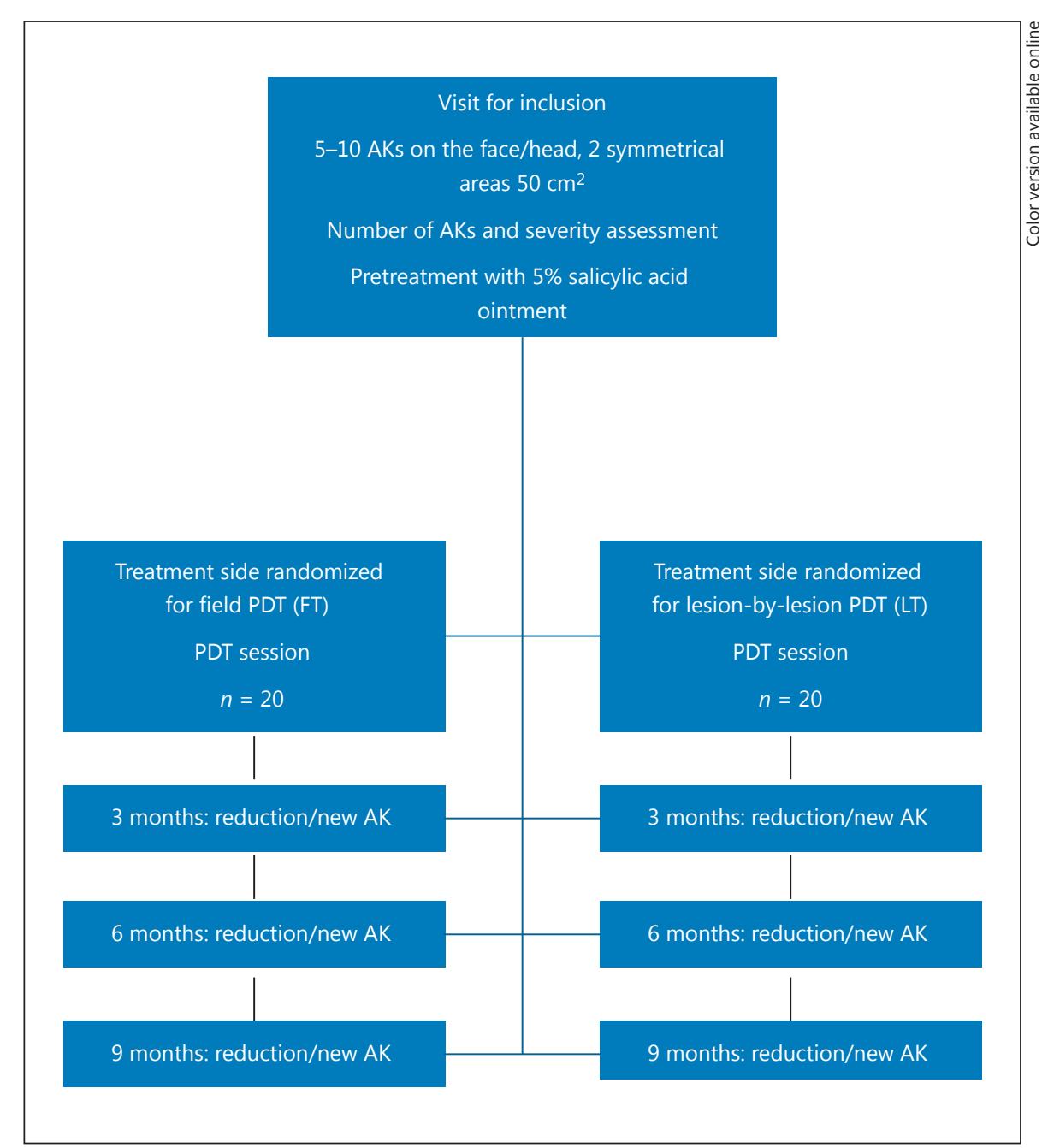

vix is part of the photodynamic therapy (MAL-PDT). MAL-PDT involves the use of photochemical reactions mediated through the interaction of porphyrins, light, and oxygen for the treatment of superficial skin malignancies. MAL-PDT is a 2-step procedure. Firstly, MAL is applied to the patients' skin and allowed to be taken up in the skin cells. This leads to the accumulation of protoporphyrin IX (PpIX) in the target cells. The next step involves the activation of PpIX in the presence of oxygen and red light, the latter performed by a light source. Because the photosensitizer is preferentially absorbed by the target cells, PDT minimizes damage to adjacent healthy skin. At present, the protocol involves the application of a layer of MAL (approximately $1 \mathrm{~mm}$ thick) to the lesion and the surrounding $5 \mathrm{~mm}$ of normal skin. The treated area should be covered with an occlusive dressing such as Tegaderm. In this way, AK lesions are treated separately.
However, in the past years, the concept of field cancerization has been widely accepted [3-7]. AKs have been described to be a field disease and not limited to single clinically apparent lesions. In the definition of field cancerization, clinically normal-appearing skin surrounding AKs and SCCs contains subclinical features of genetically damaged cells which may develop into new AKs or SCCs. The presence of field cancerization indicates a high-risk population with subclinical invisible disease, multiple primary tumours, local recurrences, and premalignant change, which requires repeated treatments and causes significant morbidity [3-7]. Treatment should therefore target an area of field change which may reduce the risk of development of further AKs, second tumours, and local recurrence. Unfortunately, to date there are no studies which compare the efficacy of lesion-by-lesion treatment with field treatment with MAL-PDT [8].
Actinic Keratoses: "Lesion-by-Lesion" and Field Photodynamic Therapy
Dermatology 2016;232:708-714 DOI: $10.1159 / 000453610$ 
Table 1. Baseline characteristics

\begin{tabular}{|c|c|c|c|}
\hline & $\begin{array}{l}\text { Lesional treatment } \\
(n=20)\end{array}$ & $\begin{array}{l}\text { Field treatment } \\
(n=20)\end{array}$ & $p$ value \\
\hline \multicolumn{4}{|l|}{ Sex, $n(\%)$} \\
\hline Male & $19(95.0)$ & $19(95.0)$ & \\
\hline Female & $1(5.0)$ & $1(5.0)$ & \\
\hline \multicolumn{4}{|l|}{ Age, years } \\
\hline Mean \pm SD & $73.7 \pm 6.4$ & $73.7 \pm 6.4$ & \\
\hline Range & $60-87$ & $60-87$ & \\
\hline \multicolumn{4}{|l|}{ Race, $n(\%)$} \\
\hline Caucasian & $20(100)$ & $20(100)$ & \\
\hline AK lesions per group, $n$ & 172 & 179 & \\
\hline \multicolumn{4}{|l|}{ AK lesions per patient, $n$} \\
\hline Mean \pm SD & $8.6 \pm 1.6$ & $9.0 \pm 1.2$ & 0.301 \\
\hline Median (range) & $9.0(6-10)$ & $9.0(6-10)$ & \\
\hline \multicolumn{4}{|l|}{ Severity grade, $n(\%)$} \\
\hline Mild (slight palpability, Olsen grade I) & $154(89.5)$ & $155(86.6)$ & 0.809 \\
\hline Patients, $n$ & 20 & 20 & \\
\hline Mean \pm SD & $7.7 \pm 1.9$ & $7.8 \pm 2.0$ & 0.914 \\
\hline Median (range) & $7.5(4-10)$ & $8.0(3-10)$ & \\
\hline Moderate (moderately thick, Olsen grade II) & $18(10.5)$ & $24(13.4)$ & 0.084 \\
\hline Patients, $n$ & 20 & 20 & \\
\hline Mean \pm SD & $0.9 \pm 1.4$ & $1.2 \pm 1.6$ & 0.156 \\
\hline Median (range) & $0(0-5)$ & $0(0-5)$ & \\
\hline Severe (thick, Olsen grade III) & 0 & 0 & \\
\hline \multicolumn{3}{|l|}{ Total lesion area, $\mathrm{cm}^{2}$} & 0.968 \\
\hline Mean \pm SD & $49.6 \pm 20.4$ & $49.1 \pm 21.7$ & \\
\hline Range & $23.0-91.4$ & $21.5-103.6$ & \\
\hline \multicolumn{4}{|l|}{ Localization, $n(\%)$} \\
\hline Face & $9(45.0)$ & $9(45.0)$ & \\
\hline Scalp & $11(55.0)$ & $11(55.0)$ & \\
\hline
\end{tabular}

We conducted a single-centre, prospective, randomized, split-face, investigator-blinded study, in which patients were randomized for one side to be treated with field PDT and the other side with "lesion-by-lesion" PDT.

Our primary objective was to assess the number of new lesions at 9 months after PDT. Secondary objectives were to determine the number of new lesions at 3 and 6 months after treatment and the percentage reduction of AKs from baseline at 3, 6, and 9 months after treatment.

\section{Materials and Methods}

For further details, see the supplementary materials (for all online suppl. material, see www.karger.com/doi/10.1159/000453610) (Fig. 1).

\section{Results}

At baseline, we found no significant differences in number and severity of AKs between both treatment sides. The mean number of AKs was $8.6 \pm 1.6$ (LT side) versus $9 \pm 1.2$ (FT side). Nine patients were treated for AKs in the face and 11 for AKs on the scalp. Both sides showed comparable cosmetic scores at baseline; $80 \%$ of the patients had been previously treated for AKs, and $70 \%$ had a history of non-melanoma skin cancers (Table 1).

At 3, 6, and 9 months after a single session, we found a significant reduction $(p=0.009)$ of lesions in both areas. At 3 months in both sides, $70 \%$ of the patients showed a complete or excellent response, whereas $30 \%$ showed fair or poor responses. The mean lesion reduction was $7.0 \pm$ $2.3(81.1 \pm 21 \%$; LT $)$ versus $7.2 \pm 1.8(80.8 \pm 17.5 \%$; FT $)$. The mean number of new AKs was $0.8 \pm 1.4$ (LT) versus 
Table 2. Patient and lesion response at 3 months

\begin{tabular}{|c|c|c|c|}
\hline & $\begin{array}{l}\text { Lesional treatment } \\
(n=20)\end{array}$ & $\begin{array}{l}\text { Field treatment } \\
(n=20)\end{array}$ & $p$ value \\
\hline \multicolumn{4}{|l|}{ Patient response, $n(\%)$} \\
\hline Response $(75-100 \%)$ & $14(70.0)$ & $14(70.0)$ & \\
\hline Complete response (100\%) & $7(35.0)$ & $5(25.0)$ & \\
\hline Excellent (partial) response (75-99\%) & $7(35.0)$ & $9(45.0)$ & \\
\hline No response $(0-74 \%)$ & $6(30.0)$ & $6(30.0)$ & \\
\hline Fair response $(50-74 \%)$ & $4(20.0)$ & $5(25.0)$ & \\
\hline Poor response $(25-49 \%)$ & $2(10.0)$ & $1(5.0)$ & \\
\hline No response $(0-24 \%)$ & 0 & 0 & \\
\hline \multicolumn{4}{|l|}{ Lesion response } \\
\hline Lesion reduction, $n$ & 140 & 143 & \\
\hline Mean \pm SD & $7.0 \pm 2.3$ & $7.2 \pm 1.8$ & 0.981 \\
\hline Range & $2-10$ & $3-10$ & \\
\hline \multicolumn{4}{|l|}{ Lesion reduction, \% } \\
\hline Mean \pm SD & $81.1 \pm 21.0$ & $80.8 \pm 17.5$ & 0.669 \\
\hline Median (range) & $87.3(33.3-100.0)$ & $85.4(42.9-100.0)$ & \\
\hline Remaining AKs, $n$ & 33 & 34 & 0.717 \\
\hline Mean \pm SD & $1.7 \pm 1.8$ & $1.7 \pm 1.6$ & \\
\hline Range & $0-6$ & $0-5$ & \\
\hline \multicolumn{4}{|l|}{ Severity grade primary AKs, $n(\%)$} \\
\hline Mild (slight palpability, Olsen grade I) & $30(90.9)$ & $32(94.1)$ & 0.695 \\
\hline Moderate (moderately thick, Olsen grade II) & $3(9.1)$ & $2(5.9)$ & 0.564 \\
\hline New AKs, $n$ & 16 & 7 & 0.257 \\
\hline Mean \pm SD & $0.8 \pm 1.4$ & $0.4 \pm 0.8$ & \\
\hline Range & $0-5$ & $0-3$ & \\
\hline \multicolumn{4}{|l|}{ Severity grade new AKs, $n(\%)$} \\
\hline Mild (slight palpability, Olsen grade I) & $13(81.3)$ & $7(100)$ & 0.394 \\
\hline Moderate (moderately thick, Olsen grade II) & $3(18.7)$ & 0 & 0.180 \\
\hline
\end{tabular}

$0.4 \pm 0.8(\mathrm{FT})$. The total number of new AKs was 16 (LT) and 7 (FT), with no significant difference. Cosmetic outcome was comparable on both sides (Table 2).

At 6 months, a complete or excellent response was observed in $47 \%$ of the sides treated with LT versus $73 \%$ of the sides treated with FT. In the LT side, 53\% demonstrated a fair or poor response, whereas in the FT side, we observed these responses in only $27 \%$. The mean lesion reduction was $8.6 \pm 1.6(75.3 \pm 18.9 \%$; $\mathrm{LT})$ versus $6.7 \pm$ $2.1(76.1 \pm 20.2 \%$; FT). The mean number of new AKs was $0.7 \pm 1.1(\mathrm{LT})$ versus $0.9 \pm 1.3(\mathrm{FT})$. The total number of new AKs was 11 (LT) and 13 (FT), with no significant difference. Again, there was no difference in cosmetic outcome. At 6 months we only evaluated 15 patients: 1 patient moved abroad during the study, 1 patient switched to another hospital for follow-up, 1 patient was treated by another doctor with cryotherapy for AKs in the study areas, 1 patient diseased, and 1 patient was unable to come for the follow-up at month 6 because of intensive

Actinic Keratoses: "Lesion-by-Lesion" and Field Photodynamic Therapy radiotherapy during that period (the latter patient was fortunately able to attend the follow-up at 9 months) (Table 3).

At 9 months we evaluated 16 patients (see the aforementioned reasons for dropouts). The mean number of new AKs was $1.3 \pm 1.7(\mathrm{LT})$ versus $0.6 \pm 0.9(\mathrm{FT})$. The total number of new lesions after 9 months was 20 (LT) versus 10 (FT). In the LT sides we found a complete or excellent response in $68.8 \%$, whereas $31.2 \%$ of the patients showed fair or poor responses. In the FT side, $75 \%$ of the patients demonstrated a complete or excellent response, with $25 \%$ having fair or poor responses after 1 single session. The number of remaining AKs was significantly lower in the LT area $(p=0.013)$, whereas the number of new lesions was significantly lower in the FT side $(p=0.014)$. The mean lesion reduction was $7.0 \pm 1.9$ $(84.3 \pm 19.5 \%)(\mathrm{LT})$ versus $6.7 \pm 1.9(76.6 \pm 17.2 \%)(\mathrm{FT})$ (Table 3). Cosmetic outcome at 9 months, again, showed no differences between the two sides.

Dermatology 2016;232:708-714 
Table 3. Patient and lesion response at 9 months

\begin{tabular}{|c|c|c|c|}
\hline & $\begin{array}{l}\text { Lesional treatment } \\
(n=16)\end{array}$ & $\begin{array}{l}\text { Field treatment } \\
(n=16)\end{array}$ & $p$ value \\
\hline \multicolumn{4}{|l|}{ Patient response, $n(\%)$} \\
\hline Response $(75-100 \%)$ & $11(68.8)$ & $12(75.0)$ & \\
\hline Complete response (100\%) & $7(43.8)$ & $2(12.5)$ & \\
\hline Excellent (partial) response $(75-100 \%)$ & $4(25.0)$ & $10(62.5)$ & \\
\hline No response $(0-74 \%)$ & $5(31.2)$ & $4(25.0)$ & \\
\hline Fair response $(50-74 \%)$ & $4(25.0)$ & $3(18.8)$ & \\
\hline Poor response $(25-49 \%)$ & $1(6.3)$ & $1(6.3)$ & \\
\hline No response $(0-24 \%)$ & 0 & 0 & \\
\hline \multicolumn{4}{|l|}{ Lesion response } \\
\hline Lesion reduction $^{\mathrm{a}}, n$ & 112 & 107 & \\
\hline Mean \pm SD & $7.0 \pm 1.9$ & $6.7 \pm 1.9$ & 0.308 \\
\hline Range & $3-10$ & $3-10$ & \\
\hline \multicolumn{4}{|l|}{ Lesion reduction, \% } \\
\hline Mean \pm SD & $84.3 \pm 19.5$ & $76.6 \pm 18.5$ & 0.006 \\
\hline Median (range) & $88.9(30.0-100)$ & $78.9(30.0-100)$ & \\
\hline Remaining AKs, $n$ & 23 & 33 & 0.013 \\
\hline Mean \pm SD & $1.4 \pm 1.9$ & $2.1 \pm 1.8$ & \\
\hline Range & $0-7$ & $0-7$ & \\
\hline \multicolumn{4}{|l|}{ Severity grade primary AKs, $n(\%)$} \\
\hline Mild (slight palpability, Olsen grade I) & $12(52.2)$ & $28(84.8)$ & 0.003 \\
\hline Moderate (moderately thick, Olsen grade II) & $11(47.8)$ & $5(15.2)$ & 0.109 \\
\hline New AKs, $n$ & 20 & 10 & 0.016 \\
\hline Mean \pm SD & $1.3 \pm 1.7$ & $0.6 \pm 0.9$ & \\
\hline Median (range) & $1.0(0-6)$ & $0(0-3)$ & \\
\hline \multicolumn{4}{|l|}{ Severity grade new AKs, $n(\%)$} \\
\hline Mild (slight palpability, Olsen grade I) & $14(70.0)$ & $8(80.0)$ & 0.096 \\
\hline Moderate (moderately thick, Olsen grade II) & $6(30.0)$ & $2(20.0)$ & 0.102 \\
\hline
\end{tabular}

\section{Discussion}

The reported risk of malignant transformation of an AK to an SCC ranges from less than 0.025 to $20 \%$ per year. Although the exact rate of malignant transformation to SCC is unknown, the majority of SCCs appear to arise from within AKs [9]. Guenthner et al. [10] examined 1,011 SCC specimens. In 983 lesions (97.2\%), they found histopathological changes consistent with SCC in situ at the periphery or within the confines of the existing SCC. Lober et al. [11] examined 26 SCCs to determine the histological presence of concomitant SCC in situ at the margins. SCC in situ was present in 24/26 cases on initial examination; SCCs in situ were also found in additional sections from the residual 2 SCCs. The main issue is that we do not know which AK will evolve into an invasive SCC. For this reason, the AK is commonly treated [12].
As early as 1953, Slaughter et al. [3] introduced the term "field cancerization" and linked it to the recurrence of oral cancer and second primary tumours. Organs involved in field cancerization include head and neck SCCs, upper digestive tract, colon, lung, vulva, cervix, breast, bladder, and skin. Field cancerization of the epithelia is currently a widely accepted concept in cancer biology as a manifestation of cancer progression [3-7]. The concept of field cancerization suggests that clinically normal-appearing skin surrounding AKs and SCCs has subclinical features of genetically damaged cells which may develop into new AKs or SCCs. Therefore, it may be worthwhile to treat the whole area with AKs.

To date, no studies have been published on a comparison between LT-PDT and FT-PDT in patients with field cancerization. The present in-patient comparison study showed a significant reduction in the number of AKs in 

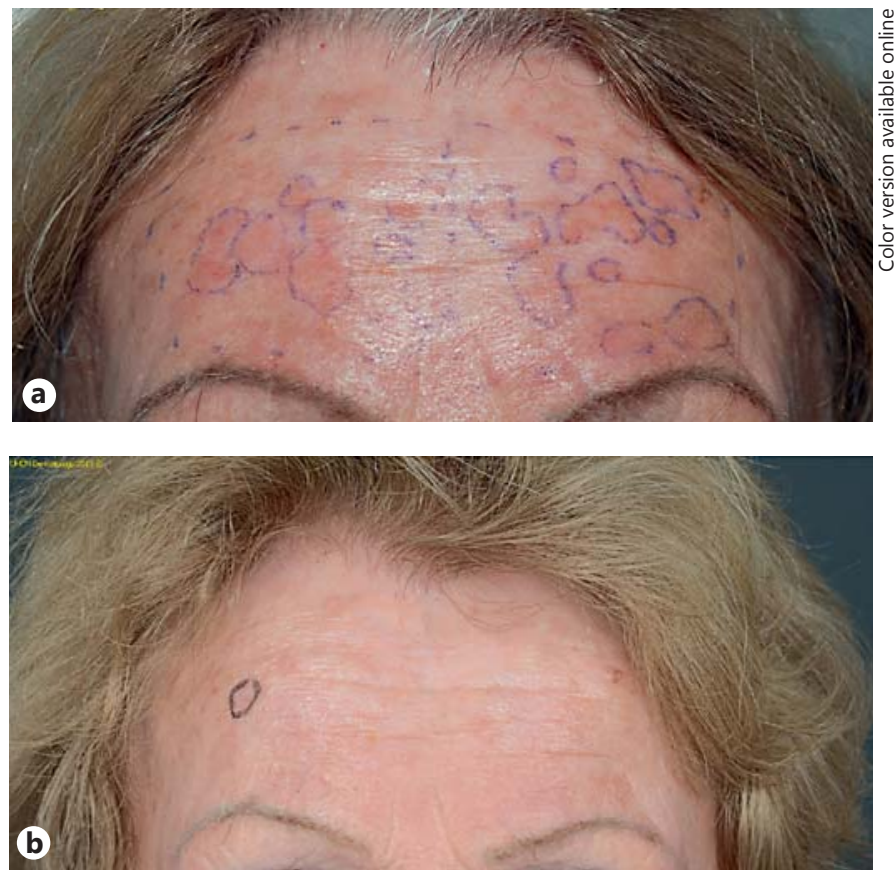

Fig. 2. Results of field treatment. a Baseline. b Nine months.

the LT as well as in the FT sides at every time point during the follow-up. After 3 and 6 months we did not observe significant differences between both sides. However, 9 months after treatment, the LT area showed significantly fewer remaining AKs, whereas the FT area demonstrated significantly fewer new lesions. A recent systematic review reported that rates of regression of single lesions ranged between 15 and $63 \%$ after 1 year, which could explain why our results appeared better at 9 months compared with earlier time points [13].

The cosmetic results were comparable at all time points. In 6 patients results were better at month 9; 15 AKs disappeared during this follow-up at 6 months, corresponding to a mean of 2.5 .

The results may well reflect the fact that when treating a mean of 8-9 AKs in a field size of $50 \mathrm{~cm}^{2}$, we are approaching a field treatment (see Fig. 2). One may also consider that in order to get best results it may be advisable, when performing a field treatment, to apply the cream to the whole area, followed by extra attention to the application of the cream on the visible lesions.

Although there are no studies on an in-patient comparison between LT and FT, there are some papers on the efficacy of field PDT. In 2010, Apalla et al. [14] investigated whether field PDT would prevent new non-mela- noma skin cancers in patients with field cancerization. They treated 45 patients with AKs symmetrically distributed over the face or scalp with conventional ALA-PDT (aminolevulinic acid-PDT) on one side and with placebo PDT on the other side. A significant delay in the mean time of appearance and a reduction in the number of new lesions were observed in the field PDT protocol compared with the control. They concluded that field therapy with ALA-PDT confers a significant preventive potential against the formation of new non-melanoma skin cancers in patients with field changes.

Several studies, predominantly in organ transplant recipients on long-term immunosuppressive medication, reported that field PDT can delay and reduce the frequency of new non-melanoma skin cancers [15]. Most studies, however, suggest that in these cases repeated PDT sessions are necessary, with the present consensus that PDT can prevent AKs, and potentially SCCs, in transplant recipients [15-17].

Bagazgoitia et al. [18] showed the potential for PDT to reduce actinic damage and elastosis, and to significantly decrease the expression of Ki-67 and TP53. The expression of cyclin D1 remained stable. The fact that a single PDT session was not sufficient to clear early oncogenic markers supports the belief that repeated treatments are necessary to optimize the preventive effect of PDT. Szeimies et al. [19] reported on the clinical, histological, and immunohistochemical effects of 3 consecutive treatments with MAL-PDT on photodamaged skin with multiple AKs in immunocompetent patients. In addition to clearing $90 \%$ of visible AKs, a significant decrease in keratinocyte atypia in clinically normal skin was reported. An increase in collagen deposition and improvement in solar elastosis was also observed. The decrease in TP53 expression, however, was not significant. Thus, we may conclude that there is evidence that PDT has the potential to reduce the carcinogenic potential in areas of field cancerization.

In conclusion, with respect to treatment and prevention, there is some evidence for superiority of field treatment compared with placebo in terms of new AK prevention. Our present in-patient comparative study also shows that, as stated above, field treatment is superior to lesionby-lesion treatment with respect to the development of new lesions. It may, however, be worthwhile to perform a new study in which larger treatment areas are compared in order to better compare field versus lesion-by-lesion treatment. 


\section{Statement of Ethics}

The study was approved by the ethics committee. All patients gave written consent to participate in the study.

\section{Disclosure Statement}

This study was financially supported by Galderma International. I. Seubring received financial support from Galderma for performing clinical trials. M.-J.P. Gerritsen received speaker's honoraria from Galderma, 3M, and Medac, and joined the advisory boards of Galderma and Leo Pharma. Furthermore, she received financial support from PhotoCure, Galderma, Leo Pharma, and $3 \mathrm{M}$ for performing clinical trials.

\section{References}

1 Dutch Society of Dermatology and Venereology: Dutch guideline "actinic keratosis". Utrecht, Dutch Society of Dermatology and Venereology, 2010.

-2 Van Rijsingen M, Seubring I, Maessen-Visch B, Lavrijsen S, van Bergen B, Groenewoud J, Gerritsen MJ: Insight into the number of premalignancies and malignancies of the skin in a hospital population in the Netherlands. Eur J Dermatol 2015;25:261-265.

3 Slaughter DP, et al: Field cancerization in oral stratified squamous epithelium; clinical implications of multicentric origin. Cancer 1953;6:963-968.

-4 Ha PK, Califano JA: The molecular biology of mucosal field cancerization of the head and neck. Crit Rev Oral Biol Med 2003;14:363369.

5 Tabor MP, Brakenhoff RH, Ruijter-Schippers $\mathrm{HJ}$, et al: Multiple head and neck tumors frequently originate from a single preneoplastic lesion. Am J Pathol 2002;161:1051-1060.

6 Kanjilal S, Strom SS, Clayman GL, et al: p53 mutations in nonmelanoma skin cancer of the head and neck: molecular evidence for field cancerization. Cancer Res 1995;55:36043609.

7 Braakhuis BJ, Tabor MP, Kummer JA, Leemans CR, Brakenhoff RH: A genetic explanation of Slaughter's concept of field cancerization: evidence and clinical implications. Cancer Res 2003;63:1727-1730.
>8 Field Philipp-Dormston WG: Cancerization: from molecular basis to selective field-directed management of actinic keratosis. Curr Probl Dermatol 2015;46:115-121.

$\checkmark 9$ Czarnecki D, Meehan CJ, Bruce F, Culjak G: The majority of cutaneous squamous cell carcinomas arise in actinic keratoses. J Cutan Med Surg 2002;6:207-209.

10 Guenthner ST, et al: Cutaneous squamous cell carcinomas consistently show histologic evidence of in situ changes: a clinicopathologic correlation. J Am Acad Dermatol 1999;41: 443-448.

11 Lober BA, et al: Actinic keratosis is squamous cell carcinoma. J Am Acad Dermatol 2000;43. 881-882.

12 Holmes C, et al: Solar keratosis: epidemiology, pathogenesis, presentation and treatment: Australas J Dermatol 2007;48:67-74.

13 Werner RN, Sammain A, Erdmann R, Hartmann V, Stockfleth E, Nast A: The natural history of actinic keratosis: a systematic review. Br J Dermatol 2013;169:502-518.

14 Apalla Z, Sotiriou E, Chovarda E, et al: Skin cancer: preventive photodynamic therapy in patients with face and scalp cancerization. A randomized placebo-controlled study. $\mathrm{Br} \mathrm{J}$ Dermatol 2010;162:171-175.
15 Basset-Seguin N, Baumann Conzett K, Gerritsen M-J, Gonzalez H, Haedersdal M, Hofbauer G, Aguado L MD, Kerob D, Lear JT, Piaserico S, Ulrich C: Photodynamic therapy for actinic keratosis in organ transplant patients. J Eur Acad Dermatol Venereol 2013; 27:57-66.

$>16$ Togsverd-Bo K, Omland SH, Wulf HC, Sørensen SS, Haedersdal M: Primary prevention of skin dysplasia in renal transplant recipients with photodynamic therapy: a randomized controlled trial. Am J Transplant 2015; 15: 2986-2990.

17 Wulf HC, Pavel S, Stender I, Bakker-Wensveen CAHB: Topical photodynamic therapy for prevention of new skin lesions in renal transplant recipients. Acta Derm Venereol 2006;86:25-28.

18 Bagazgoitia L, Cuevas Santos J, Juarranz A, Jaen P: Photodynamic therapy reduces the histological features of actinic damage and the expression of early oncogenic markers. Br J Dermatol 2011;165:144-151.

19 Szeimies RM, Torezan L, Niwa A, Valente N, Unger P, Kohl E, Schreml S, Babilas P, Karrer S, Festa-Neto C: Clinical, histopathological and immunohistochemical assessment of human skin field cancerization before and after photodynamic therapy. Br J Dermatol 2012; 167:150-159. 